\title{
Evaluation of official tropical cyclone track forecast over north Indian Ocean issued by India Meteorological Department
}

\author{
M Mohapatra*, D P Nayak, R P Sharma and B K Bandyopadhyay \\ India Meteorological Department, Mausam Bhavan, Lodi Road, New Delhi 110 003, India. \\ *Corresponding author. e-mail: mohapatraimd@gmail.com
}

India Meteorological Department (IMD) introduced the objective tropical cyclone (TC) track forecast valid for next $24 \mathrm{hr}$ over the north Indian Ocean (NIO) in 2003. It further extended the validity period up to $72 \mathrm{hr}$ in 2009. Here an attempt is made to evaluate the TC track forecast issued by IMD during 20032011 (9 years) by calculating the direct position error (DPE) and skill in track forecast. The accuracy of TC track forecast has been analysed with respect to basin of formation (Bay of Bengal, Arabian Sea and NIO as whole), season of formation (pre-monsoon and post-monsoon seasons), intensity of TCs (cyclonic storm and severe cyclonic storm or higher intensities) and type of track of TCs (climatological/straight moving and recurving/looping type). The average DPE is about 140, 262 and $386 \mathrm{~km}$ and skill is about $27 \%, 39 \%$ and $50 \%$, respectively for 24,48 and $72 \mathrm{hr}$ forecasts over the NIO as a whole during 20092011. Though the DPE is higher and skill is less as compared to those in northwest Pacific and north Atlantic Ocean, the rate of decrease (increase) in DPE (skill) is higher over the NIO in recent years. The DPE (skill) over the NIO has decreased (increased) at the rate of about $7.3 \mathrm{~km} \mathrm{(3 \% )} \mathrm{per} \mathrm{year} \mathrm{during}$ 2003-2011 for $24 \mathrm{hr}$ forecasts.

\section{Introduction}

One of the more neglected components of poststorm analysis of tropical cyclone (TC) is the routine preparation of best tracks and detailed forecast performance statistics at the end of each season when more raw data and complete history of TC are available. Whilst this is a time-consuming task, which uses valuable resources, it provides the best possible storm archive, together with invaluable information on overall forecast performance and the relative performance of individual techniques. Such information is essential for:

- Developing new forecasting techniques and monitoring forecast improvements resulting from new algorithms, techniques and observing systems;
- Evaluation of value addition by forecasters to guidance received from the objective aids;

- Providing a basis for objectively estimating forecast uncertainty, which is used in deciding the timing and extent of warnings and watches, especially for critical regions;

- Providing feedback on the relative accuracy of available forecast techniques, perhaps including stratification into different synoptic, latitudinal, or seasonal types (e.g., Neumann and Pelissier 1981).

All the above is essential, as the most fundamental parameter in TC prediction is a storm's location or track. Improved short range (1-3 days) track forecasts lead to fewer unnecessary warnings and evacuations. It is due to the fact that the prediction

Keywords. Tropical cyclone; north Indian Ocean; track; direct position error; skill. 
of severe weather like storm surge depends on the predicted time and place of landfall, direction of movement towards land (crossing angle), speed of movement, etc. Similarly, the prediction of area and time of occurrence of heavy rainfall and gale wind along the coast depends on predicted track of the TC (IMD 2003). So, a better track forecast will yield improved forecasts of wind speed, storm surge, and precipitation along the coast during landfall of a TC.

IMD, as one of the six Regional Specialised Meteorological Centres (RSMCs), is responsible for TC monitoring and prediction over the north Indian Ocean (NIO). A cyclonic disturbance (CD) is considered as a TC over the NIO, when the associated maximum sustained surface wind (MSW) is 34 knots or more as per the classification adopted by IMD. It corresponds to the definition of tropical storms over other ocean basins like Pacific and Atlantic Oceans. Detailed classification of TCs into cyclonic storm (CS), severe cyclonic storm (SCS), very severe cyclonic storm (VSCS) and super cyclonic storm (SuCS) are given in cyclone manual published by IMD (2003). The depressions (with MSW) of 17-33 knots and TCs constitute the CDs over the NIO (IMD 2003).

IMD introduced the objective TC track forecast valid for next $24 \mathrm{hr}$ over the NIO in 2003. It further extended the validity period up to $72 \mathrm{hr}$ in 2009. It may be mentioned that the RSMC, Tokyo introduced $24 \mathrm{hr}$ objective forecast in 1982, $48 \mathrm{hr}$ forecast in 1988, $72 \mathrm{hr}$ forecast in 1997 and 96 and $120 \mathrm{hr}$ forecast in 2009 for northwest Pacific Ocean (RSMC, Tokyo 2011). Similarly, National Hurricane Centre (NHC) and RSMC, Miami, USA introduced $24 \mathrm{hr}$ objective forecast in 1954, $48 \mathrm{hr}$ forecast in 1961, $72 \mathrm{hr}$ forecast in 1972, and 96 and $120 \mathrm{hr}$ forecast in 2001 for Atlantic Ocean (NHC 2012). Prior to 2003, the TC forecasts issued by IMD for the NIO were subjective and textual in form without mentioning expected location of the TC in 12 and $24 \mathrm{hr}$ forecast period.

Most of the TC forecasting centres including NHC, USA and RSMC, Tokyo verify their TC track forecasts regularly on yearly basis. RSMC, New Delhi introduced the objective TC forecast verification in 2009 (RSMS, New Delhi 2010). The TC forecast errors can be analysed from several perspectives. The most common is the absolute track error or direct position error (DPE). The DPE is the great circle distance between a TC's forecast position and the observed position at the forecast verification time.

In order to compare forecasts made in extremely variable conditions like quasi-stationary/fast moving TCs, recurving/looping of TCs and rapidly intensifying/dissipating TCs and evaluate their quality by including these forecasts' degree of difficulty (in particular with the aim of detecting forecasts' trends with time), there are several possible options. The first, being the measurement of gain (or loss) in skill in forecast in relation to a reference model. In other words, an essential component of the error analysis is to normalise all forecast errors by a standard technique. Climatology and persistence (CLIPER) model is a statistical forecast technique which is used as a standard in most of the TC forecasting centres as the standard technique to calculate the skill in track forecast. Here, an attempt is made to evaluate the TC track forecast issued by IMD during 2003-2011 (9 years) based on the calculation of DPE and skill in track forecast.

The forecaster's awareness of the abovementioned track forecast error measures represents an important factor in the overall decision process relative to the formulation of TC warnings and advisories (Simpson 1971). It is due to the fact that though the TC track forecasts have been steadily improving for several decades, some uncertainty still remains due to variation in track forecast errors with respect to type of track, season of formation and intensity of the TC, etc. For example, in a very severe TC with climatological track such as TC, Thane (25-30 December 2011, figure 1), the average 24 and $48 \mathrm{hr}$ track forecast errors were 77 and $160 \mathrm{~km}$, respectively. On the other hand, in a very severe TC with recurving track such as TC, Phet (31 May-7 June, 2010, figure 1), the average 24 and $48 \mathrm{hr}$ track forecast errors were 162 and $311 \mathrm{~km}$, respectively. A part of this uncertainty is also due to an inherent predictability limit that future improvements in numerical models and in forecasting techniques will not be able to overcome (Fraedrich and Leslie 1989; Plu 2011). Therefore, end users of TC forecasts, such as risk managers and public agencies, need both reliable track forecasts and an estimation of the forecast uncertainty. A measure of standard error in track forecast is represented in the form of cone of uncertainty (COU) in the track forecast. The depiction of uncertainty in track forecast in the form of $\mathrm{COU}$ helps the disaster managers to decide upon the area of evacuation and mobilization of resources for TC disaster mitigation. Hence, apart from the utilities as mentioned in the first paragraph, this study can be utilized to interpret the track forecast properly and decide effective cyclone management response actions by the disaster managers. To determine the COU in track forecast, it is essential to know the track forecast errors and skill in the past years. For construction of the COU in track forecast, an uncertainty circle is built for each forecast lead time, whose radius is based on the distribution of DPE computed 


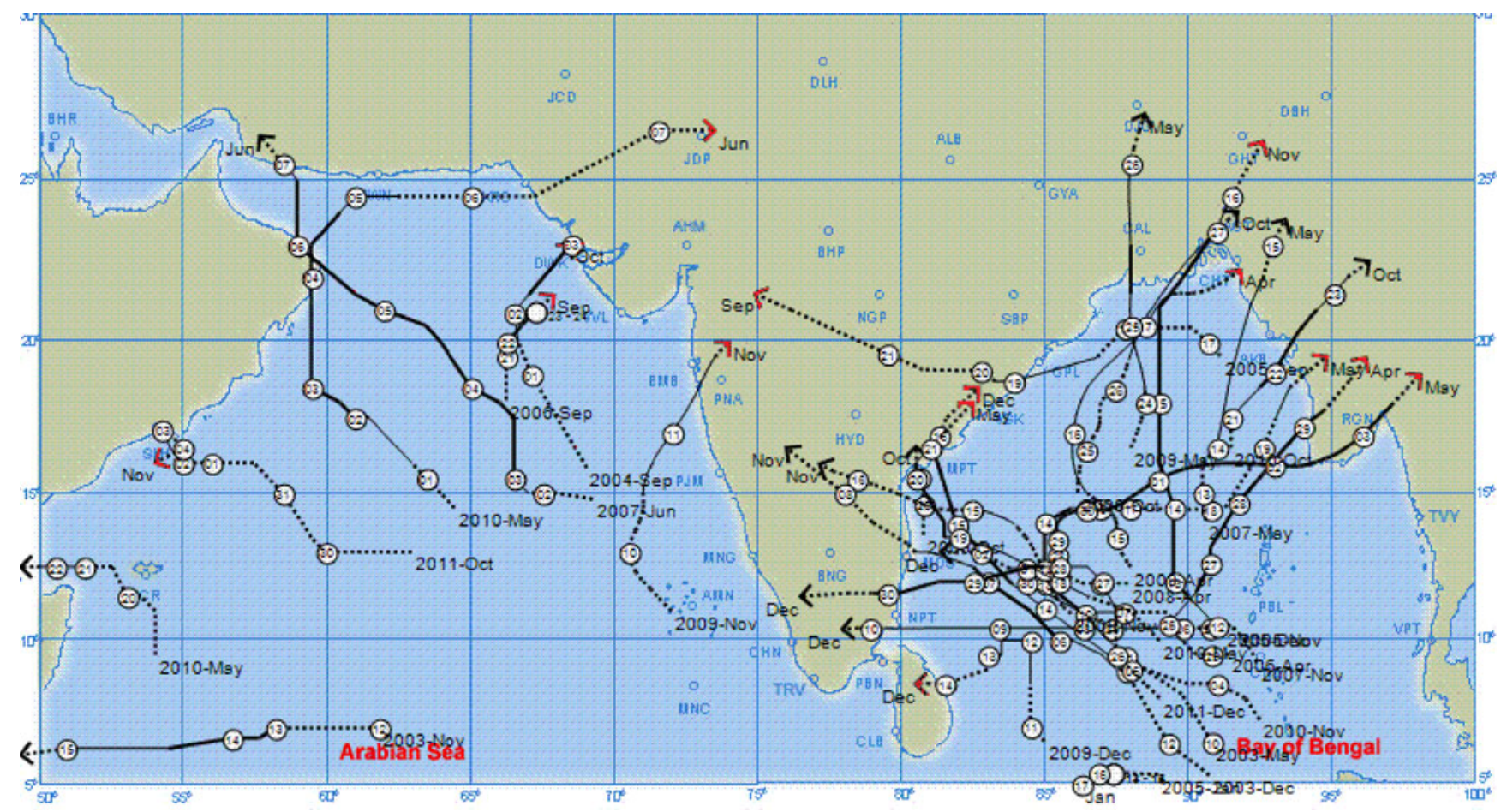

Figure 1. Tracks of TCs during 2003-2011 under consideration in the study. Tracks ending with red colour arrows are recurving/looping tracks and others are climatological/straight moving tracks.

over several previous seasons (Dupont et al. 2011). IMD at present uses the average forecast error for past five years based on official forecast and quasi Lagrangian model (QLM) to construct $\mathrm{COU}$ in track forecast.

This study can also be utilised to further fine tune the COU definition used by IMD as track forecast errors gradually decrease over the years. The fine tuning of the COU may also demand adoption of some new techniques or algorithms. As the uncertainty in a track forecast is dependent on the atmospheric conditions of that forecast, dynamic predictions of uncertainty are expected to be superior. For example, in a high-predictability scenario such as a TC propagating westward/ northwestward for days along the southern periphery of a subtropical ridge, the uncertainty (and therefore warning area) may be considerably smaller than a low-predictability scenario such as a TC that recurves northeastwards/southwestwards. Hence there is a need for development of COU forecast model using dynamical model forecasts of track and intensity of TCs. The ensemble prediction system (EPS) is such an approach, which aims to provide probabilities (and distributions) based purely on the flow and its inherent uncertainty governed by the spread in the numerical weather prediction (NWP) model. So, this study can be used to evaluate and adapt the EPS based COU in track forecast of TCs.

\section{Data and methodology}

The data sample for evaluation of track forecast is composed of the tracks of all TCs with different intensities (cyclonic storm and above) over the NIO (north of equator and between longitude $45^{\circ}$ and $\left.100^{\circ} \mathrm{E}\right)$, over the period of nine years $(2003-2011)$. The track forecast has been issued by RSMC, New Delhi from deep depression stage onwards since 2009 for 12, 24, 36, 48, 60 and $72 \mathrm{hr}$ forecast periods. It has been issued during CS stage onwards during 2003-2008 and for 12 and $24 \mathrm{hr}$ forecast periods only. The TC forecast issued 4 times a day at the interval of six hours, i.e., based on 00, 06, 12 and 18 UTC observations valid up to $24 \mathrm{hr}$ during 2003-2008 and up to $72 \mathrm{hr}$ during 2009-2011 have been considered for evaluation of forecast performance. The forecasts are issued about three hours after the above-mentioned observation time.

IMD follows a standard operation procedure (SOP) for monitoring and forecasting of TCs over the NIO. The detailed procedure is discussed in cyclone manual published by IMD (2003). Basically, the forecast tracks result from a manually analyzed forecasting process, which relies on output from several NWP models (RSMC 2010) including IMD Global Forecast system (GFS), European centre for Medium range Weather forecast (ECMWF), the UK Meteorogical Office, Japan Meteorological Agency (JMA), ARP-Meteo-France, National 
Centre for Environmental Prediction (NCEP) GFS and some ensemble means like multi-model ensemble (MME). Consensus forecasts that gather all or part of the numerical forecast tracks and uses synoptic and statistical guidance are utilised to issue official forecast.

A total of 28 TCs during 2003-2011 (figure 1) has been considered in the study including 20 over the Bay of Bengal (BoB) and 8 over the Arabian Sea (AS). Detailed characteristics of the TCs considered in the study are given in table 1 . The total number of forecast verified for all forecast lengths $(12,24,36,48,60$ and $72 \mathrm{hr})$ is 671 including 261 , $222,70,51,39$ and 28 numbers of forecast for 12 , $24,36,48,60$ and $72 \mathrm{hr}$ lead periods, respectively (table 2). The number of such forecasts decreases with increase in forecast length, as some of the CDs have less life period and some weaken below the intensity of deep depression within $72 \mathrm{hr}$ of their genesis (figure 1).
All the TC track forecasts issued by IMD have been verified against the observed track of IMD. In this study, the DPE and skill of track forecast have been calculated for all the TCs during 20032008 for 12 and $24 \mathrm{hr}$ forecast and during 20092011 for 12, 24, 36, 48, 60 and $72 \mathrm{hr}$ forecast. The observed TC positions are taken from the official RSMC best-track dataset (IMD 2012). An example of calculation of the DPE based on forecast track and the observed best track is shown in figure 2 . The DPE is measured by the distance between the RSMC forecast and the RSMC best-track position at the corresponding forecast verification time.

In order to measure the skill in track forecast, the CLIPER model has been used as a reference model. The CLIPER model is based on combination of persistence forecast using the past $12 \mathrm{hr}$ trend in motion of the current TC and climatological forecast of movement of TC using the data of past years. The climatological forecast assumes

Table 1. Details of the tropical cyclones (TCs) under consideration.

\begin{tabular}{|c|c|c|c|c|c|c|c|}
\hline Sl. no. & Year & Life period & $\begin{array}{l}\text { Maximum } \\
\text { intensity }\end{array}$ & $\begin{array}{l}\text { Basin of } \\
\text { formation }\end{array}$ & $\begin{array}{l}\text { Season of } \\
\text { formation }\end{array}$ & $\begin{array}{c}\text { Type of } \\
\text { track of } \mathrm{TC}\end{array}$ & $\begin{array}{c}\text { Landfalling/ } \\
\text { dissipating TC }\end{array}$ \\
\hline 1 & 2003 & 10-19 May & VSCS & BoB & $\mathrm{PM}$ & $\mathrm{R}$ & $\mathrm{L}$ \\
\hline 2 & 2003 & 12-15 November & SCS & $\mathrm{AS}$ & $\mathrm{PS}$ & $\mathrm{S} / \mathrm{C}$ & $\mathrm{D}$ \\
\hline 3 & 2003 & 11-16 December & VSCS & $\mathrm{BoB}$ & PS & $\mathrm{R}$ & $\mathrm{L}$ \\
\hline 4 & 2004 & 30 September-3 October & SCS & $\mathrm{AS}$ & $\mathrm{PS}$ & $\mathrm{R}$ & $\mathrm{L}$ \\
\hline 5 & 2005 & 13-17 January & $\mathrm{CS}$ & $\mathrm{BoB}$ & Winter & $\mathrm{S} / \mathrm{C}$ & $\mathrm{D}$ \\
\hline 6 & 2005 & 17-21 September & CS & $\mathrm{BoB}$ & Monsoon & $\mathrm{R}$ & $\mathrm{L}$ \\
\hline 7 & 2005 & 28 November-2 December & CS & BoB & $\mathrm{PS}$ & $\mathrm{S} / \mathrm{C}$ & $\mathrm{D}$ \\
\hline 8 & 2005 & 6-10 December & CS & $\mathrm{BoB}$ & $\mathrm{PS}$ & $\mathrm{S} / \mathrm{C}$ & $\mathrm{L}$ \\
\hline 9 & 2006 & 25-29 April & VSCS & $\mathrm{BoB}$ & $\mathrm{PM}$ & $\mathrm{R}$ & $\mathrm{L}$ \\
\hline 10 & 2006 & 21-24 September & SCS & $\mathrm{AS}$ & Monsoon & $\mathrm{R}$ & $\mathrm{D}$ \\
\hline 11 & 2006 & 29-30 October & $\mathrm{CS}$ & BoB & $\mathrm{PS}$ & $\mathrm{S} / \mathrm{C}$ & $\mathrm{L}$ \\
\hline 12 & 2007 & 13-15 May & $\mathrm{CS}$ & BoB & $\mathrm{PM}$ & $\mathrm{S} / \mathrm{C}$ & $\mathrm{L}$ \\
\hline 13 & 2007 & 1-7 June & $\mathrm{SuCS}$ & $\mathrm{AS}$ & Monsoon & $\mathrm{S} / \mathrm{C}$ & $\mathrm{L}$ \\
\hline 14 & 2007 & 11-16 November & VSCS & $\mathrm{BoB}$ & $\mathrm{PS}$ & $\mathrm{R}$ & $\mathrm{L}$ \\
\hline 15 & 2008 & 27 April-3 May & VSCS & BoB & $\mathrm{PM}$ & $\mathrm{R}$ & $\mathrm{L}$ \\
\hline 16 & 2008 & 25-27 October & CS & $\mathrm{BoB}$ & $\mathrm{PS}$ & $\mathrm{S} / \mathrm{C}$ & $\mathrm{L}$ \\
\hline 17 & 2008 & 13-16 November & CS & BoB & PS & $\mathrm{S} / \mathrm{C}$ & $\mathrm{L}$ \\
\hline 18 & 2009 & 14-17 April & CS & BoB & PM & $\mathrm{R}$ & $\mathrm{L}$ \\
\hline 19 & 2009 & 23-26 May & SCS & $\mathrm{BoB}$ & PM & $\mathrm{S} / \mathrm{C}$ & $\mathrm{L}$ \\
\hline 20 & 2009 & 9-12 November & CS & $\mathrm{AS}$ & $\mathrm{PS}$ & $\mathrm{R}$ & $\mathrm{L}$ \\
\hline 21 & 2009 & 10-15 December & $\mathrm{CS}$ & $\mathrm{BoB}$ & PS & $\mathrm{R}$ & $\mathrm{L}$ \\
\hline 22 & 2010 & 17-21 May & SCS & BoB & $\mathrm{PM}$ & $\mathrm{R}$ & $\mathrm{L}$ \\
\hline 23 & 2010 & 19-23 May & $\mathrm{CS}$ & AS & $\mathrm{PM}$ & $\mathrm{S} / \mathrm{C}$ & $\mathrm{D}$ \\
\hline 24 & 2010 & 31 May-7 June & VSCS & AS & $\mathrm{PM}$ & $\mathrm{R}$ & $\mathrm{L}$ \\
\hline 25 & 2010 & 20-23 October & VSCS & BoB & $\mathrm{PS}$ & $\mathrm{S} / \mathrm{C}$ & $\mathrm{L}$ \\
\hline 26 & 2010 & 4-8 November 2010 & SCS & BoB & PS & $\mathrm{S} / \mathrm{C}$ & $\mathrm{L}$ \\
\hline 27 & 2011 & 29 October-4 November & CS & $\mathrm{AS}$ & PS & $\mathrm{R}$ & $\mathrm{L}$ \\
\hline 28 & 2011 & 25-31 December & VSCS & BoB & PS & $\mathrm{S} / \mathrm{C}$ & $\mathrm{L}$ \\
\hline
\end{tabular}

CS: Cyclonic storm, SCS: Severe cyclonic storm, VSCS: Very severe cyclonic storm, SuCS: Super cyclonic storm.

BoB: Bay of Bengal, AS: Arabian Sea, R: Recurving/looping, S/C: straight moving/climatological, L: Landfalling, D: Dissipating over sea, PM: Pre-monsoon, PS: Post-monsoon. 
Table 2. Statistics of official six hourly track forecasts verified during 2003-2011.

\begin{tabular}{|c|c|c|c|c|c|c|c|c|c|}
\hline \multirow{4}{*}{$\begin{array}{l}\text { Forecast } \\
\text { period } \\
(\text { hrs })\end{array}$} & \multirow{2}{*}{\multicolumn{3}{|c|}{ Basin of formation }} & & & \multirow{2}{*}{\multicolumn{2}{|c|}{ Type of track }} & \multicolumn{2}{|c|}{ Intensity of CD } \\
\hline & & & & & & & & \multirow[b]{3}{*}{$\begin{array}{c}\mathrm{CS} \\
(13)\end{array}$} & \multirow{3}{*}{$\begin{array}{c}\text { SCS and } \\
\text { higher } \\
\text { intensity } \\
\quad(15)\end{array}$} \\
\hline & \multirow[b]{2}{*}{$\begin{array}{l}\text { BoB } \\
(20)\end{array}$} & \multirow[b]{2}{*}{$\begin{array}{l}\mathrm{AS} \\
(8)\end{array}$} & \multirow{2}{*}{$\begin{array}{c}\mathrm{NIO} \\
(\mathrm{BoB}+\mathrm{AS}) \\
(28)\end{array}$} & \multicolumn{2}{|c|}{ Season of formation } & \multirow{2}{*}{$\begin{array}{c}\text { Climatological/ } \\
\text { straight moving } \\
(14)\end{array}$} & \multirow{2}{*}{$\begin{array}{c}\text { Recurving/ } \\
\text { looping } \\
(14)\end{array}$} & & \\
\hline & & & & $\begin{array}{c}\text { Pre-monsoon } \\
(10)\end{array}$ & $\begin{array}{c}\text { Post-monsoon } \\
(18)\end{array}$ & & & & \\
\hline 12 & 195 & 66 & 261 & 122 & 139 & 104 & 157 & 75 & 186 \\
\hline 24 & 164 & 58 & 222 & 106 & 116 & 80 & 142 & 54 & 168 \\
\hline 36 & 49 & 21 & 70 & 33 & 37 & 26 & 44 & 20 & 50 \\
\hline 48 & 33 & 18 & 51 & 25 & 26 & 17 & 34 & 11 & 40 \\
\hline 60 & 24 & 15 & 39 & 20 & 19 & 12 & 27 & 7 & 32 \\
\hline 72 & 14 & 14 & 28 & 18 & 10 & 8 & 20 & 2 & 26 \\
\hline Total & 479 & 192 & 671 & 324 & 347 & 247 & 424 & 169 & 502 \\
\hline
\end{tabular}

Figures given within parentheses in the first row indicate the number of TCs.

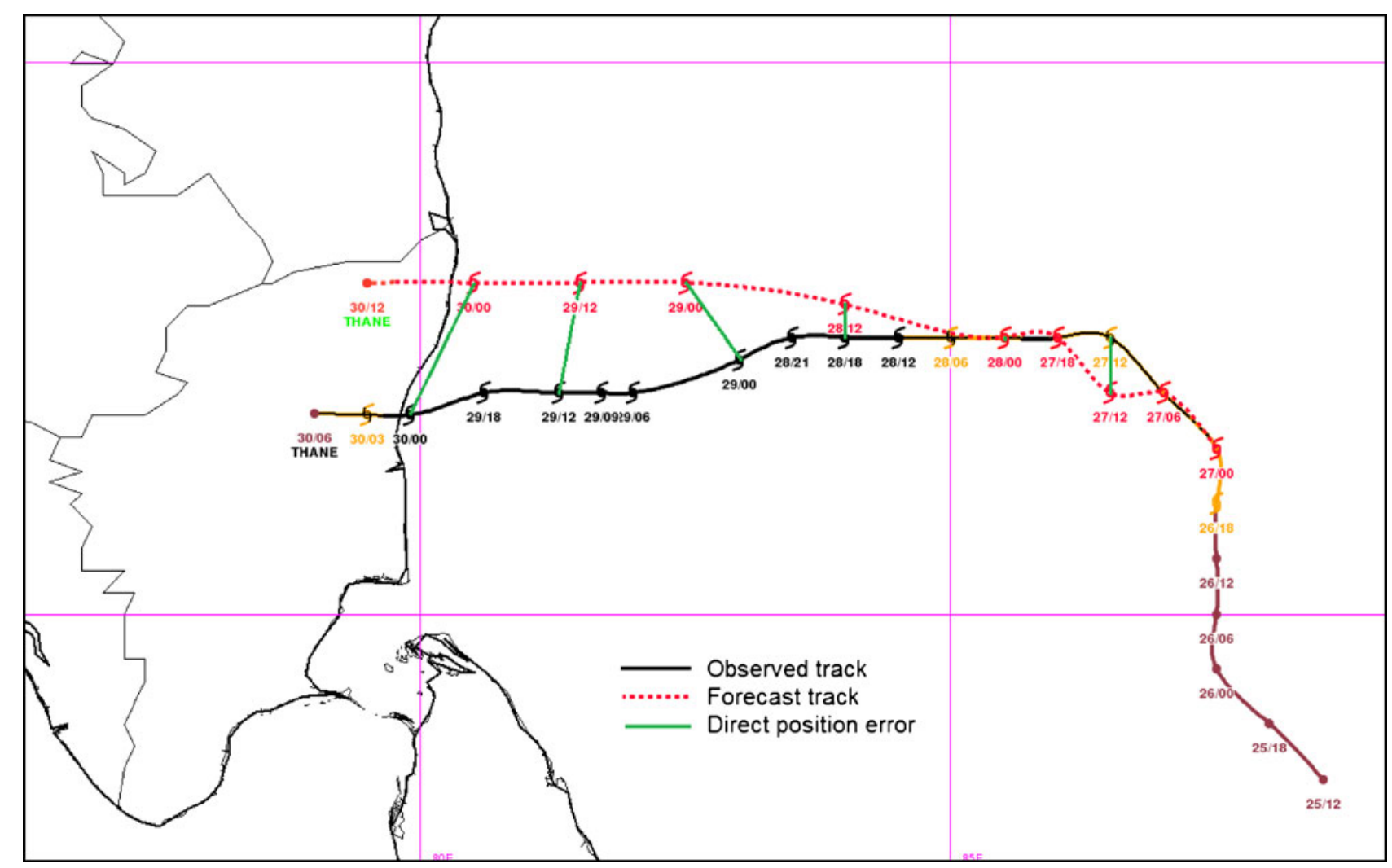

Figure 2. An example of forecast track based on 0000 UTC of 27 December 2011, observed track of very severe cyclonic storm, Thane (25-30 December 2011) and the direct position error at different forecast verification time.

that TC will move with average speed and direction of all past TCs near that location. Since CLIPER is based entirely on current position and motion and derives its forecast from past storms, techniques that do not improve on this have no real skill. This normalisation also allows a ready comparison between 'easy' and 'difficult' forecast years and different ocean basins (Pike and Neumann 1987). Thus, CLIPER is an excellent measure of forecast difficulty and normalising all forecasts by the CLIPER errors provides a homogeneous indication of forecast skill. In this study, the CLIPER model suggested by Neumann and Mandal (1978) has been used to calculate the DPE of CLIPER model with respect to TCs over the NIO. This CLIPER model gives equal weightage to persistence and climatological forecasts.

The gain in skill in relation to CLIPER, is quantified in percentage terms by:

$$
\text { Gain in skill }=\frac{(\text { CLIPER DPE }- \text { DPE })}{\text { CLIPER DPE }} \times 100 \%
$$


The accuracy of TC track forecast has been analysed with respect to basin of formation (BoB, AS and NIO as whole), season of formation (premonsoon and post-monsoon seasons), intensity of TCs (CS and SCS or higher intensities) and type of track of TCs (climatological/straight moving and recurving/looping type) by calculating DPE and skill separately. The dataset include 13 CS and 15 SCS or higher intensity (table 2). The TCs show bi-modal behaviour in their genesis with primary maxima in post-monsoon season (OctoberDecember) and secondary maxima in pre-monsoon season (March-May). There have been nine TCs in pre-monsoon and 15 TCs in post-monsoon season respectively out of 28 TCs considered in the study. There have been three TCs during monsoon months (one in June and two in September) and another in winter season (table 1). Since the TC in the month of June 2007 (SN 13 of table 1) occurred during onset phase of monsoon, it had pre-monsoon characteristics. So it has been considered as the TC in pre-monsoon season for analysis purpose. Similarly, the TCs in September (SN 6 and 10 of table 1) have been considered in the category of the post-monsoon season, as it occurred during withdrawal phase of monsoon. The only cyclone in winter season (January-February) has also been considered in the post-monsoon season category, as it occurred in the northeast monsoon phase in January 2005 (SN 5 of table 1). As such, there are 10 and 18 TCs during pre-monsoon and postmonsoon seasons respectively. The performance of TC track forecast has been analysed during these two seasons separately, as their track, genesis and intensification characteristics are different in these two different seasons.

The results are analysed and presented in section 3 . The limitations and future scope are presented in section 4. The broad conclusions are presented in section 5 .

\section{Results and discussion}

The DPE and skill have been analysed with respect to basin of formation (NIO as a whole, BoB and AS) of TCs, type of track, intensity of TCs (CS and SCS or higher intensities) and season of formation (pre-monsoon and post-monsoon) and the results are presented and discussed in subsections 3.1-3.4. The interannual variations in the DPE and skill are analysed and discussed in subsection 3.5.

\subsection{Average DPE and skill in TC track forecast}

The statistics of DPE and track forecast skill are shown in figure $3(\mathrm{a}$ and $\mathrm{b})$ respectively. It is found that the average DPE during 2003-2011 is about $148 \mathrm{~km}$ for $24 \mathrm{hr}$ forecast. Considering the
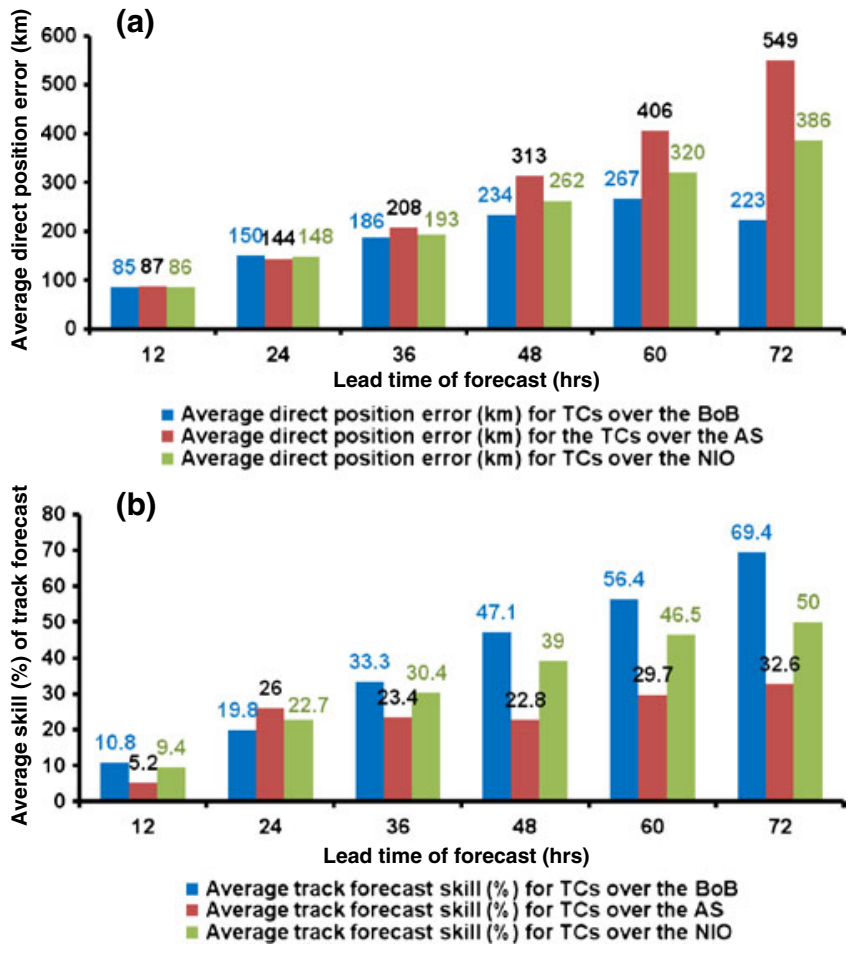

Figure 3. (a) Average direct position error (km) and (b) skill of track forecast issued by IMD for the TCs over the BoB, AS and NIO as a whole.

Table 3. Average track forecast error ( $\mathrm{km}$ ) and skill (\%) of IMD for TCs over the NIO during 2009-2011.

\begin{tabular}{lccc}
\hline $\begin{array}{l}\text { Forecast } \\
\text { period (hrs) }\end{array}$ & $\begin{array}{c}\text { Track } \\
\text { error (km) }\end{array}$ & Skill (\%) & $\begin{array}{c}\text { Number of } \\
\text { forecasts verified }\end{array}$ \\
\hline 12 & 72 & 22.3 & 109 \\
24 & 140 & 26.9 & 93 \\
36 & 193 & 30.3 & 70 \\
48 & 262 & 39.0 & 51 \\
60 & 320 & 46.5 & 39 \\
72 & 386 & 50.0 & 28 \\
\hline
\end{tabular}

period of 2009-2011 when there has been significant improvement in monitoring and prediction of TCs over the NIO due to modernisation programme of IMD, the DPE is about 140, 262 and $386 \mathrm{~km}$ for 24,48 and $72 \mathrm{hr}$ forecasts, respectively (table 3 ). It increases with increase in forecast length like other ocean basins. Comparing the DPE over the NIO with that over the other TC basins, it is found that the DPE over the NIO is higher than that over the northwest Pacific and north Atlantic Oceans. The average DPE of NHC, USA for the TCs over the northern Atlantic Ocean during 2003-2011 is about 95, 150 and $250 \mathrm{~km}$ for 24, 48 and $72 \mathrm{hr}$ forecasts, respectively (NHC 2012). Similarly, the DPE of RSMC, Tokyo for the TCs over the northwest Pacific Ocean is about 
113, 208 and $310 \mathrm{~km}$ for 24,48 and $72 \mathrm{hr}$ forecasts respectively during 2003-2011 (RSMC, Tokyo 2011). The lower accuracy over the NIO may be due to the fact that the NIO is a data sparse region compared to northwest Pacific and north Atlantic Oceans, as there is no aircraft probing facility in the NIO unlike the northwest Pacific and north Atlantic Oceans. Further, the in-situ data from the meteorological buoys are significantly less over the NIO, with only five buoys working during 2003-2010 and 12 in 2011 (Mohapatra et al. 2012). Scarcity of observational data leads to poor initial condition in NWP models. The poor initial condition leads to increase in forecast error of NWP models (Mohanty et al. 2010; Osuri et al. 2012), which are the backbone for official track forecast of TCs, especially in 36-72 hr forecast range. However, better initial condition is not the sufficient condition for improvement of track forecast. The higher resolution, better physical parameterization and consideration of physical processes like oceanatmosphere coupling and assimilation of various remotely sensed and directly observed data are also necessary for improvement in track forecast by NWP models.

Considering the skill of track forecast, it is about $23 \%$ for $24 \mathrm{hr}$ forecast period during 2003-2011. Considering the period of 2009-2011, the skill of track forecast is about $27 \%, 39 \%$ and $50 \%$ for 24 , 48 and $72 \mathrm{hr}$ forecasts (figure $3 \mathrm{~b}$ ). Comparing with that over the north Atlantic and northwest Pacific, the skill is also less over the NIO. The average skill of NHC, USA for the TCs over the north Atlantic Ocean during 2003-2011 is about 45\%, 55\% and $54 \%$ for 24,48 and $72 \mathrm{hr}$ forecasts, respectively (NHC 2012). The skill over the NIO thus lags from that over north Atlantic Ocean by about 22\%, $16 \%$ and $4 \%$ for 24,48 and $72 \mathrm{hr}$ forecast periods. Similarly, the skill of RSMC, Tokyo for the TCs over the northwest Pacific Ocean is about 51\%, 58\% and $62 \%$ for 24,48 and $72 \mathrm{hr}$ forecasts, respectively during 2003-2010 (RSMC, Tokyo 2011). It may be mentioned that the skill of TC track forecast by RSMC, Tokyo is calculated based on persistence method as standard reference method. Hence it shows higher skill even compared to that over the north Atlantic Ocean by NHC, USA. The skill forecast by NHC, USA is based on CLIPER model as the reference model like that for the NIO by RSMC, New Delhi.

\subsection{Average DPE and skill in track forecast with respect to basin of formation of TCs}

The statistics of DPE and skill in track forecasts are shown in figure 3 for the TCs over BoB and AS. There are 20 and eight TCs in BoB and AS respectively during 2003-2011. There are 479 and 192 cases of track forecasts for different forecast lengths (table 2) for TCs over the BoB and AS respectively. It is found that there is no significant difference in DPEs over the BoB and AS for the 12, 24 and $36 \mathrm{hr}$ forecasts. However, the DPE is less over the BoB than over the AS for 48 to $72 \mathrm{hr}$ forecasts by about 80, 140 and $325 \mathrm{~km}$, respectively. Considering the skill in track forecast (figure $3 \mathrm{~b}$ ), the skill is also generally higher over the $\mathrm{BoB}$ for all forecast lengths under consideration except $24 \mathrm{hr}$ forecast. The difference in skill increases with increase in forecast length. The higher accuracy over the BoB may be attributed to the fact that the open sea area, which is a data sparse region is relatively less in case of $\mathrm{BoB}$ than in $\mathrm{AS}$. While there is a dense observatory network along the coast surrounding the $\mathrm{BoB}$ due to dense coastal observatories and cyclone detection radars, the coastal area surrounding AS does not have such a network. It leads to more accurate determination of location and intensity over $\mathrm{BoB}$ than in AS (Mohapatra et al. 2012). The higher initial error in location and intensity estimation of CDs over the AS leads to higher track forecast error (Mohanty et al. 2010; Osuri et al. 2012). Another reason for higher DPE over the AS may be due to the fact that the percentage of recurving/looping TCs is higher over the AS than over the BoB. While five out of eight (63\%) TCs over the AS are recurving/looping type, it is nine out of $20(45 \%)$ over the $\mathrm{BoB}$, which are recurving/looping type.

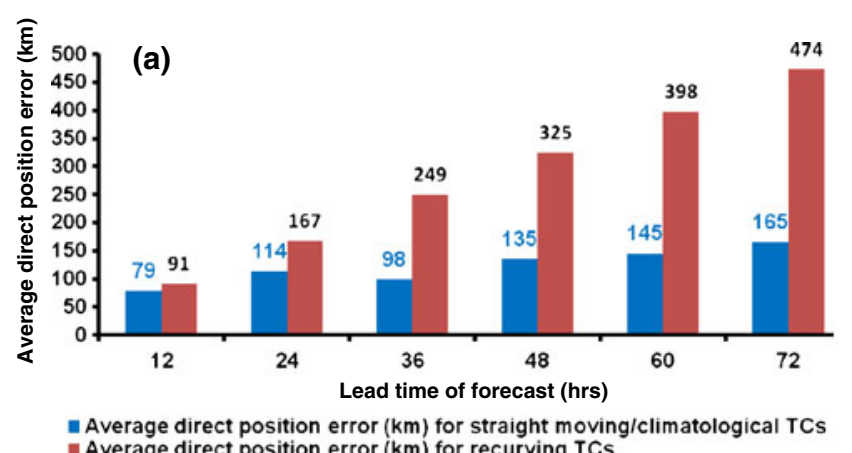
= Average direct position error $(\mathrm{km})$ for recurving TCs

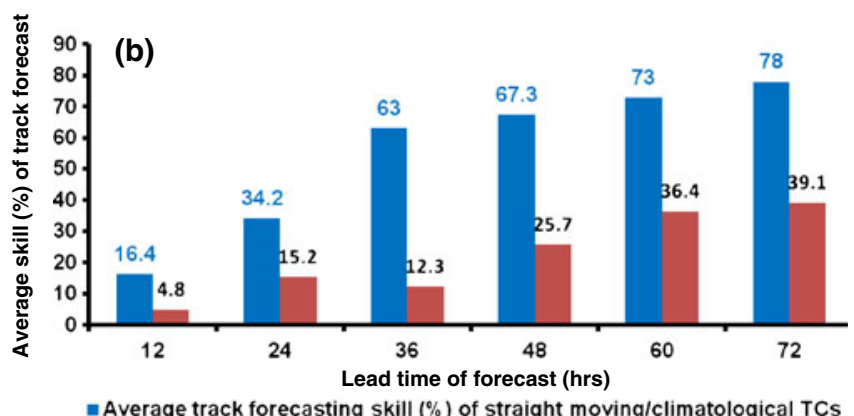
\# Average track forecasting skill $(\%)$ of straight moving/climatological TCs =Average track forecasting skill $(\%)$ of recurving TCs

Figure 4. (a) Average direct position error (km) and (b) skill of track forecast issued by IMD for the straight moving/climatological TCs and recurving/looping TCs over NIO. 
3.3 Average DPE and skill in track forecast with respect to nature of the track and season of formation of TCs

As it is evident from figure 1, the TCs follow different track characteristics. It is a well established fact that the predictability is less in case of recurving and looping TCs and more in case of straight moving TCs. Neumann and Pelissier (1981) have demonstrated it over the Atlantic Ocean based on official forecast of NHC. To find out the impact of nature of track on TC track forecast, the TCs over the NIO have been further categorized as climatological/straight moving and recurving/looping TCs and the corresponding track forecast errors have been analysed and
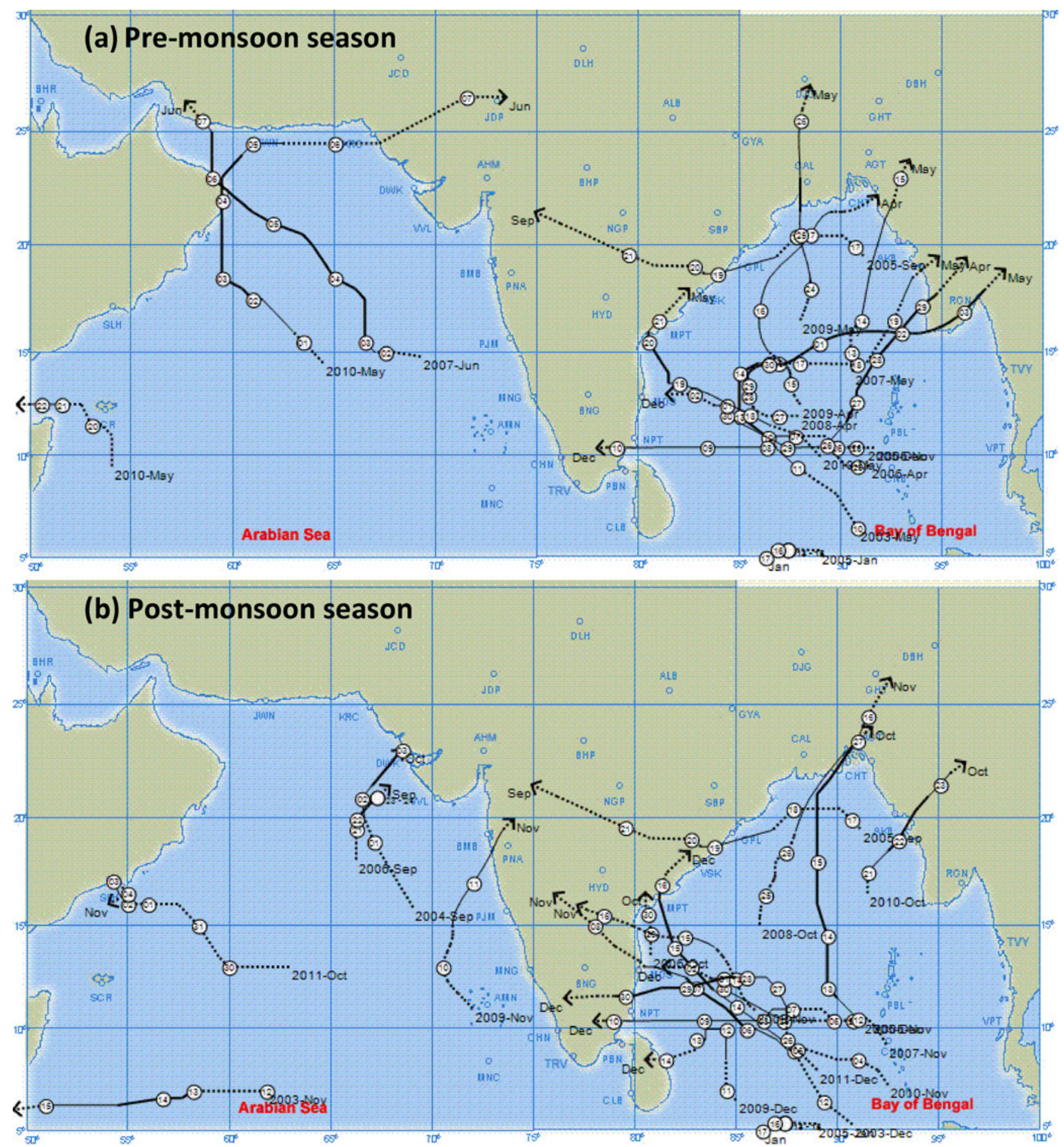

Figure 5. Tracks of TCs during (a) pre-monsoon and (b) post-monsoon seasons over the period of $2003-2011$ under consideration. 
discussed. There are 14 such TCs of different intensities in each of these two categories. There are 247 and 424 cases of track forecast for different forecast lengths (table 2) for climatological/straight moving and recurving/looping TCs respectively.

The statistics of DPE and skill in track forecast are shown in figure 4 for the climatological/ straight moving and recurving/looping TCs. It is found that the DPE is significantly higher in case of recurving TCs, being about 50, 200 and $300 \mathrm{~km}$ more for 24, 48 and $72 \mathrm{hr}$ forecasts respectively than that for the straight moving/climatologically moving TCs. Considering the skill in track forecast (figure 4b) for the above two categories of TCs, the skill is significantly higher in case of climatological/straight moving TCs and significantly less in case of recurving/looping TCs. It is less by about $19 \%, 42 \%$ and $39 \%$ for 24,48 and $72 \mathrm{hr}$ forecasts respectively than that for the straight moving/climatologically moving TCs. However, the average skill is still positive for all forecast periods indicating the fact that the method adopted is still skillful for track forecasting of recurving/looping TCs.

There are 10 and 18 TCs in pre-monsoon and post-monsoon seasons respectively considered in the study (figure 5). There are 324 and 347 cases of TC track forecasts for different forecast lengths (table 2) for TCs in pre-monsoon and postmonsoon seasons respectively during this period. The statistics of DPE and skill in track forecast are shown in figure 6 for the TCs in pre-monsoon and post-monsoon seasons. It is found that the DPE is less in case of TCs during post-monsoon season. The DPE varies from $86 \mathrm{~km}$ for $12 \mathrm{hr}$ forecast to $229 \mathrm{~km}$ for $72 \mathrm{hr}$ forecast during post-monsoon season. Considering the skill in track forecast (figure 6b), the track forecast skill is also higher in post-monsoon season than in pre-monsoon season. The difference in skill also increases with increase in forecast length. The higher accuracy during post-monsoon season may be attributed to the fact that the percentage of climatological/straight moving TCs out of total TCs is more in postmonsoon than in pre-monsoon season (figure 5). Out of 10 TCs, six (60\%) are recurving/looping type in pre-monsoon season, whereas eight out of $18\left(44^{*}\right)$ TCs are recurving/looping type in postmonsoon season. As discussed in the previous paragraph, the accuracy in track forecast is more in case of climatological/straight moving than in case of recurving/looping TCs.

\subsection{Average DPE and skill in track forecast with respect to intensity of TCs}

As the TCs intensify gradually, their location and intensity estimation become more accurate with

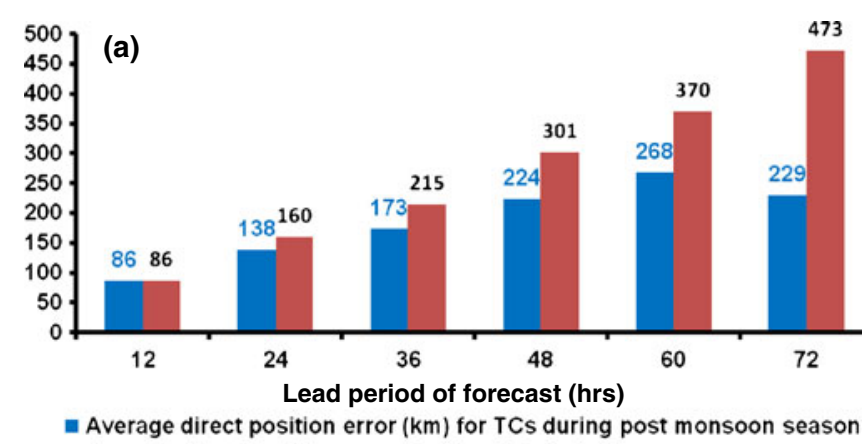

average direct position error $(\mathrm{km})$ for TCs during pre-monsoon season

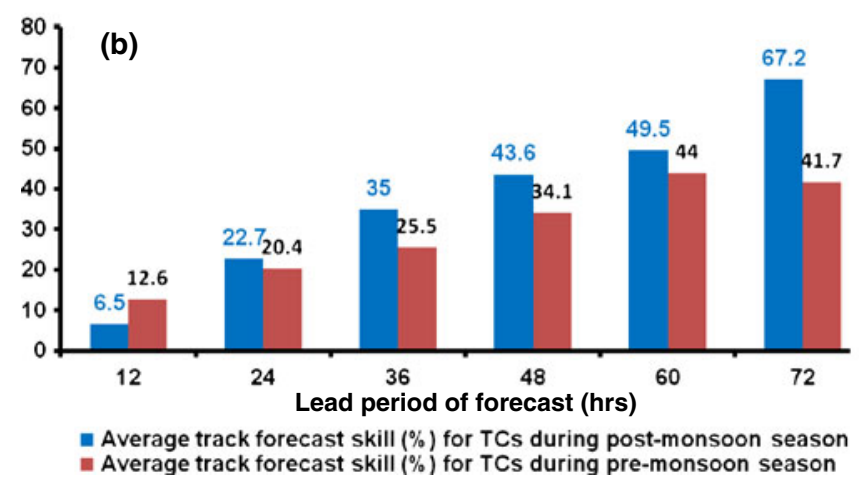

Figure 6. (a) Average direct position error (km) and (b) skill of track forecast issued by IMD for the TCs during post-monsoon and pre-monsoon seasons over NIO.

well developed characteristic features of TCs such as eye, central dense overcast (CDO) and curved band features (IMD 2003). It results in more accurate location and intensity estimation over the open seas using satellite and radar techniques. Available buoy, ship, coastal and island observations suffice the observations of satellite and radar. With more accurate determination of location and intensity, the accuracy of track forecasts increases in NWP models (Mohanty et al. 2010; Osuri et al. 2012). Hence, it is hypothesized that the official track forecast accuracy would increase with increase in intensity of TCs. To verify this hypothesis, the TCs have been classified into two categories, viz., (i) CS (maximum surface wind speed of 34-47 knots) and (ii) SCS and higher intensity (48 knots or more). The definition of the TCs analysed here is same as that adopted by IMD (2003). There are 13 and 15 TCs with intensity of CS and SCS or higher intensity respectively during 2003-2011 (figure 7). There are 169 and 502 cases of TC track forecasts for different forecast lengths (table 2) for TCs with intensity of CS and SCS or higher intensity respectively. The statistics of DPEs and skills are shown in figure 8. It is found that the DPE is less in case of SCS or higher intensity TCs. Similarly, the track forecast skill is also significantly higher in case of SCS. This result proves the hypothesis mentioned above that the track forecasting is easier in the severe TCs. 


\subsection{Interannual variation in DPE and skill of TC track forecast}

Verification of TC track forecast is important to evaluate the year on year improvement (or otherwise). So the interannual variation in TC track forecast has been analysed based on DPE and skill of forecast. The results are shown in figure 9. The DPE has decreased gradually and the skill has increased during the period of study as evident in the trend lines. The improvement in track forecast error (reduction in DPE) is about 5.9 and $7.3 \mathrm{~km} /$ year for 12 and $24 \mathrm{hr}$ forecasts, respectively during 2003-2011 (table 4). In terms of percentage improvement, it is about $7.3 \%$ and $4.2 \%$ per year respectively. The trend in improvement is statistically significant at $97.5 \%$ and 95\% level respectively for 12 and $24 \mathrm{hr}$ forecasts
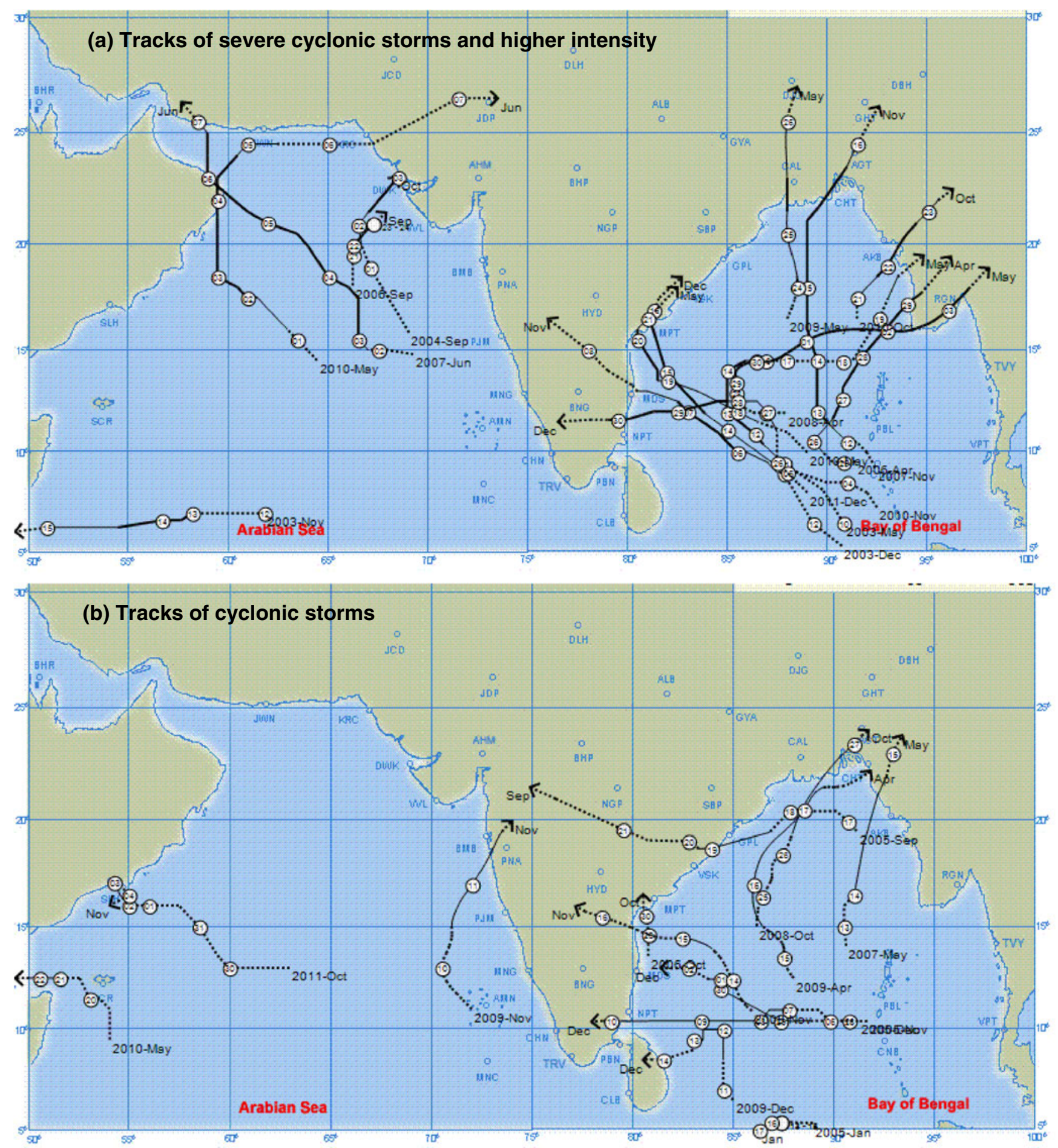

Figure 7. Tracks of (a) severe cyclonic storms and higher intensity and (b) only cyclonic storms over NIO. 

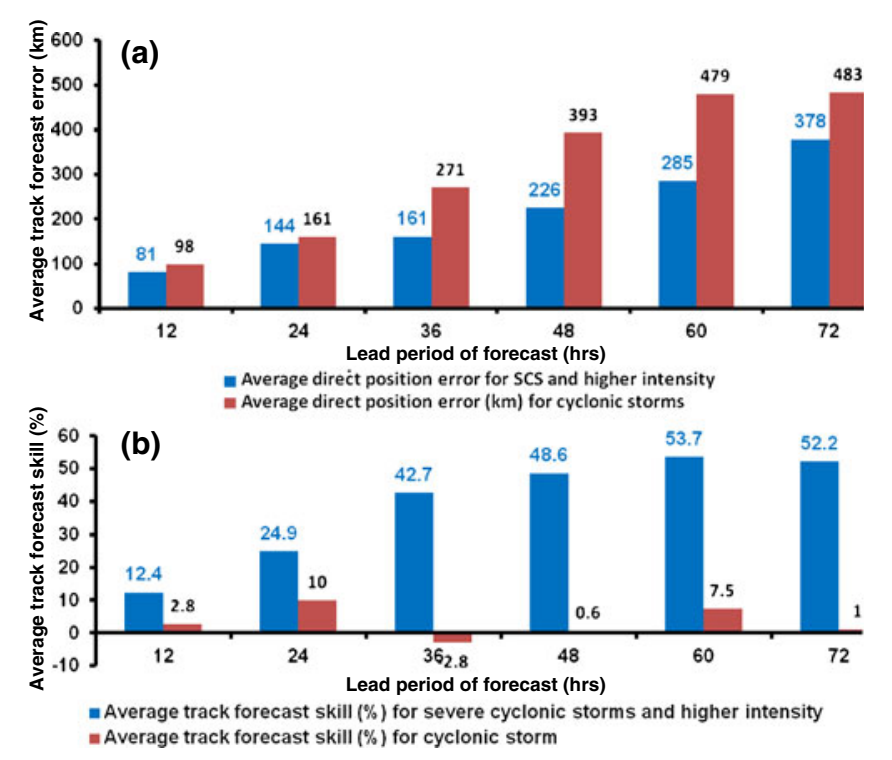

Figure 8. (a) Average direct position error (km) and (b) skill of track forecast issued by IMD for the severe cyclonic storm and higher intensity and only cyclonic storms over NIO.

according to one tailed Student's ' $t$ ' test. Considering the improvement in skill in track forecast, it has improved by about $9 \%$ and $3 \%$ per year respectively for 12 and $24 \mathrm{hr}$ forecasts and are significant at $99 \%$ and $90 \%$ level.
Comparing with the trends in northwest Pacific Ocean, it is found that the $24 \mathrm{hr}$ DPE has decreased insignificantly only at the rate of $0.9 \mathrm{~km} /$ year during 2003-2010. Accordingly, there has been improvement in skill by about $0.3 \%$ per year (RSMC, Tokyo 2011). Similarly, the rate of decrease over the north Atlantic Ocean is about $1.7 \mathrm{~km} /$ year and the skill has improved at the rate of $1.9 \%$ per year during 2003-2011 (NHC 2012). It indicates the fact that the rate of reduction in TC track forecast error has decreased significantly and hence the DPE is almost reaching the saturation stage in $24 \mathrm{hr}$ forecast range over the northwest Pacific and northern Atlantic Ocean. However, there is still scope for further reduction in $24 \mathrm{hr}$ forecast error over the NIO to about $100 \mathrm{~km}$ from the existing $140 \mathrm{~km}$ based on the latest technology including aircraft reconnaissance, deployment of buoys, assimilation of more observational data from satellite and Doppler weather radars, etc., in the NWP models.

Recent improvement in track forecast may be attributed to the improvement in the observations including:

- surface based observations through automatic weather stations (AWSs) in addition to conventional synoptic observations from manned observatories,
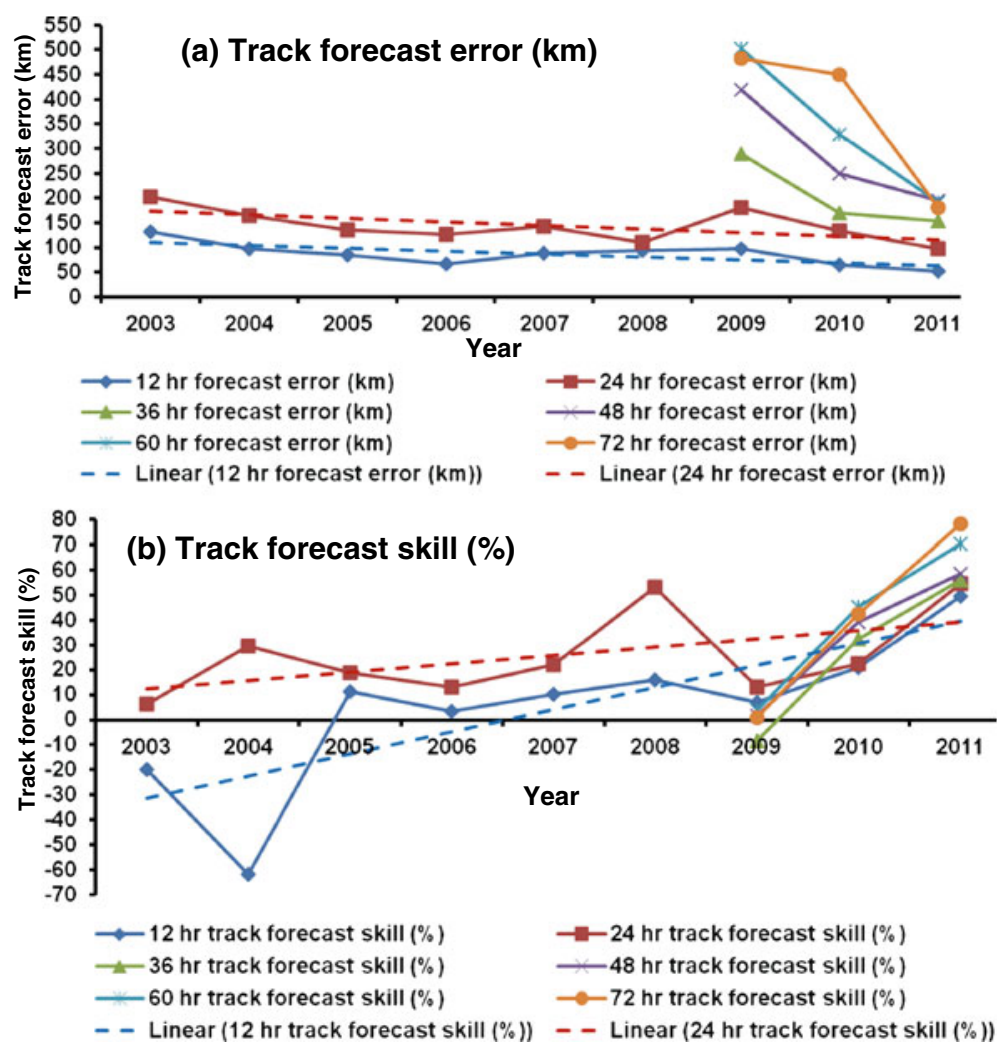

Figure 9. (a) Average track forecast error (km) and (b) track forecast skill (\%) of IMD for TCs over NIO during $2003-2011$. 
Table 4. Average annual improvement per year (IMP), variance explained (Var), statistical significance (Sig) of trend lines shown in figure 9.

\begin{tabular}{|c|c|c|c|c|c|c|c|c|}
\hline \multirow{2}{*}{$\begin{array}{l}\text { Forecast } \\
\text { period } \\
(\mathrm{hrs})\end{array}$} & \multicolumn{2}{|c|}{$\begin{array}{l}\text { IMP in track } \\
\text { forecast error }\end{array}$} & \multirow{2}{*}{$\begin{array}{c}\text { Variance } \\
(\%)\end{array}$} & \multirow{2}{*}{$\begin{array}{l}\text { Sig. level of } \\
\text { trend line }\end{array}$} & \multirow{2}{*}{$\begin{array}{c}\text { IMP in track } \\
\text { forecast skill (\%) }\end{array}$} & \multirow{2}{*}{$\begin{array}{c}\text { Variance } \\
(\%)\end{array}$} & \multirow{2}{*}{$\begin{array}{l}\text { Sig. level of } \\
\text { trend line }\end{array}$} & \multirow{2}{*}{$\begin{array}{c}\text { Number of } \\
\text { forecasts } \\
\text { verified }\end{array}$} \\
\hline & In km & In $\%$ & & & & & & \\
\hline 12 & 5.9 & 7.3 & 48.5 & $97.5 \%$ & 8.8 & 62 & $99 \%$ & 261 \\
\hline 24 & 7.3 & 4.2 & 35.8 & $95 \%$ & 3.3 & 28 & $90 \%$ & 222 \\
\hline
\end{tabular}

- upper air observations based on GPS sonde,

- Doppler weather radar observations along the coast,

- satellite based observations like surface wind through Oceansat-II and microwave imageries and products in addition to conventional visible, infrared and water vapour based imageries and products.

The enhanced observation has resulted not only in better synoptic guidance to forecaster, but also has helped in improving the initial conditions for the global and regional NWP models and hence their predictions. Further, there has been improvement in NWP capabilities through the access to array of global and regional models in recent years including IMD-GFS, ECMWF, UKMO, JMA, NCEP and Meteo-France global models, regional models like WRF and QLM and MME based on various global and regional models. Also, the tools and techniques for analysis and forecasting have improved with the introduction of Tropical Cyclone Module (TCM) in the digitised forecasting system available with the forecaster. It helps in comparing various NWP, synoptic and statistical guidance to develop a consensus track forecast of TC. Details about the improvement in observational, NWP and analysis and forecasting tools and techniques in recent years have been discussed by Mohapatra et al. (2013).

\section{Limitations and future scope}

The analysis is based on data of limited period, especially in the forecast range of $48-72 \mathrm{hr}$ period. However, the results are very interesting and in agreement with the global trend during the same period. The study has not included other measures of track forecast error, such as across track error which measures whether forecast tracks have a leftward or rightward bias and along track error which determines whether forecast tracks are slow or fast (Heming and Goerss 2010). Similarly, the study does not include the evaluation of location of landfall forecast error which is an alternative to the DPE (Powell and Aberson 2001). These two aspects are being dealt with in separate studies.

\section{Conclusions}

The following broad conclusions are drawn from the above results and discussion.

The average DPE is about 140, 262 and $386 \mathrm{~km}$ and skill is about $27 \%, 39 \%$ and $50 \%$ respectively for 24,48 and $72 \mathrm{hr}$ forecasts over the NIO as a whole during 2009-2011. Though the DPE is higher and skill is less as compared to those in northwest Pacific and north Atlantic Ocean, the rate of decrease (increase) in DPE (skill) is higher over the NIO in recent years. The DPE (skill) over the NIO has decreased (increased) at the rate of about $7.3 \mathrm{~km} \mathrm{(3 \% )} \mathrm{per} \mathrm{year} \mathrm{during} \mathrm{2003-2011} \mathrm{for}$ $24 \mathrm{hr}$ forecasts. This improvement has been possible due to improvement in observation, analysis tools and techniques and NWP modelling.

There is still scope for further reduction in track forecast error over the NIO based on the latest technology including

- further improvement in initial condition of the atmosphere and Ocean through aircraft reconnaissance and deployment of more buoys,

- assimilation of more observational data from satellite and Doppler weather radars, etc., in the NWP models,

- implementation of high resolution mesoscale ocean-atmosphere coupled model like hurricane weather research and forecast (HWRF),

- implementation of ensemble prediction system (EPS) for global and mesoscale models, and

- implementation of grand global ensemble through international collaboration, etc. IMD is already taking up all these aspects through its continuous upgradation programme.

The DPE is less and the skill is higher over the BoB than over the AS for all forecast lengths up to $72 \mathrm{hr}$. Similarly, the DPE is less and the skill is higher during the post-monsoon season than during pre-monsoon season. The DPE is also less and the skill is higher for the severe TCs than the marginal TCs. Similarly, the DPE is less and the skill is higher for climatologically moving/straight moving TCs than for the recurving/looping TCs. Comparing these results, the type of track and the intensity of the system are also the crucial factors in determining the DPE and skill of track forecasts. 


\section{Acknowledgements}

The authors are thankful to Director General of Meteorology, IMD for his support and encouragement to carry out this work. They are also thankful to Cyclone Warning Division for collection of data required for this work. The authors also thank the unknown reviewers for their valuable comments and constructive criticisms for the improvement of the manuscript.

\section{References}

Dupont T, Plu M, Caroff P and Faure G 2011 Verification of ensemble-based uncertainty circles around tropical cyclone track forecasts; Weather Forecast. 26 664-676.

Fraedrich K and Leslie M 1989 Estimates of cyclone track predictability. I: Tropical cyclones in the Australian region; Quart. J. Roy. Meteor. Soc. 115 79-92.

Heming Julian and Goerss Jim 2010 Track and structure forecasting of tropical cyclones; In: World Scientific Series on Asia Pacific Weather and Climate - Vol. 4: Global perspectives on tropical cyclones, From science to mitigation, pp. 287-323.

IMD 2003 Cyclone Manual; Published by IMD, Lodi Road, New Delhi.

IMD 2012 Tracks of cyclones and depressions over the north Indian Ocean, 1891-2011, In: Cyclone eAtlas$I M D$, Regional Meteorological Centre, 50, College Road, Chennai, India.

Mohanty U C, Osuri Krishna K, Routray A, Mohapatra M and Pattanayak Sujata 2010 Simulation of Bay of Bengal Tropical Cyclones with WRF model: Impact of initial and boundary condition; Marine Geodesy 33 294-314.

Mohapatra M, Bandyopadhyay B K and Tyagi Ajit 2012 Best track parameters of tropical cyclones over the North
Indian Ocean: A review; Nat. Hazards 63 1285-1317, doi: 10.1007/s11069-011-9935-0.

Mohapatra M, Sikka D R, Bandyopadhyay B K and Tyagi Ajit 2013 Outcomes and Challenges of Forecast Demonstration Project (FDP) on Landfalling Cyclones over the Bay of Bengal, Mausam 64 1-12.

Neumann C J and Mandal G S 1978 Statistical prediction of tropical storm motion over the Bay of Bengal and Arabian Sea; Indian J. Meteorol. Hydrol. Geophys. 29 487-500.

Neumann C J and Pelissier J M 1981 An analysis of Atlantic tropical cyclone forecast errors, 1970-1979; Mon. Weather Rev. 109 1248-1265.

NHC USA 2012 Forecast verification report, National Oceanic and Atmospheric Administration, http://www. nhc.noaa.gov/verification.

Osuri Krishna K, Mohanty U C, Routray A and Mohapatra M 2012 The impact of satellite-derived wind data assimilation on track, intensity and structure of tropical cyclones over the North Indian Ocean; Int. J. Rem. Sens. 33 1627-1652, doi: 10.1080/01431161.2011.596849.

Pike A C and Neumann C J 1987 The variation of track forecast difficulty among tropical cyclone basins; Weather Forecast. 2 237-241.

Plu Matthieu 2011 A new assessment of the predictability of tropical cyclone tracks; Mon. Weather Rev. 139 3600-3608.

Powell M D and Aberson S D 2001 Accuracy of United States tropical cyclone landfall forecasts in the Atlantic basin (1976-2000); Bull. Am. Meteorol. Soc. 82 27492767.

RSMC New Delhi 2010 Report on Cyclonic Disturbances Over The North Indian Ocean During 2009; Published by IMD, Lodi Road, New Delhi.

RSMC Tokyo 2011 Annual Report on activities of the RSMC Tokyo Typhoon Center, http://www.jma.go.jp/rsmc-hppub-eg/annualreport.html.

Simpson R H 1971 The decision process in hurricane forecasting; NOAA Tech. Memo, NWS SR-53 33p. 